\title{
MICROSCOPIC AND KELVIN PROBE STUDY OF CHARGE TRANSPORTING LAYERS ROLE IN MAPI PEROVSKITES WITH VARIED COMPOSITION
}

\author{
1*Jaroslav KULIČEK, ${ }^{1,2}$ Abasi ABUDULIMU, ${ }^{3}$ Lang LIU, ${ }^{4}$ Guilin LIU, ${ }^{3}$ Chen QI, ${ }^{1}$ Bohuslav REZEK \\ ${ }^{1}$ Faculty of Electrical Engineering, Czech Technical University, Prague, Czech Republic, EU \\ 2IMDEA Nanociencia, Madrid, Spain, EU \\ ${ }^{3}$ School of Materials and engineering, Beijing Institute of Technology, Beijing, China \\ ${ }^{4}$ School of Science, Jiangnan University, Wuxi, China \\ *kulicjar@fel.cvut.cz
}

https://doi.org/10.37904/nanocon.2019.8662

\begin{abstract}
Perovskites are one of the most intensively studied photovoltaic materials nowadays. Microscopic studies can provide useful information about material roughness, conductivity, structure, mechanical and opto-electronic properties as well as about kinetic effects from short to long time scale for understanding and improving the photovoltaic performance. Here, time-resolved photovoltage was measured by Kelvin probe in the dark and under white light illumination. Morphology was characterized by optical and atomic force microscopy. We identify the impact of charge transporting layers (CTLs) on structural and opto-electronic properties of $\mathrm{MAPbl}_{3}$ perovskite with different ratio of $\mathrm{MAl}$ and $\mathrm{Pbl}_{2}$.
\end{abstract}

Keywords: Perovskites, ionic migration, solar cells, charge transporting layers

\section{INTRODUCTION}

Perovskites are one of the most intensively studied photovoltaic materials nowadays due to their strong optical absorption, adjustable band gap, long carrier diffusion lengths, ambipolar charge transport, high carrier mobility, and high tolerance of defects [1]. They are applied in various opto-electronic devices, such as solar cells, light-emitting diodes, photodetectors, or lasers. The power conversion efficiencies (PCEs) of perovskite solar cells (PSC) have reached over $23 \%$ [2]. The hysteresis, common for various perovskite-based solar cells, has been regarded as one of the main problems to be solved. The hysteresis was described first in detail by Snaith et al. [3]. Three main causes of hysteresis were proposed: (a) interfacial traps which are filled/emptied depending on bias, (b) ferroelectric polarization, and (c) screening of the built-in electric field by mobile ions in the film. The influence of ion migration [4-6], hole transporting materials (HTMs), and grain boundaries $[7,8]$ on hysteresis was previously investigated. The research in PSC made great progress but there are still unexplained ionic defects (halides, $\mathrm{Pb}$ and methylammonium vacancies) in grain boundaries and interfaces crucially governing the devices performance and stability [9-11].

To elucidate these factors, we study here the impact of precursor stoichiometry (methylamonium (MAI) and $\mathrm{Pbl}_{2}$ ) and charge transporting layers (CTLs) on the degradation process of MAPbl 3 perovskite. The influence of CTLs $\left(\mathrm{SnO}_{2}\right.$ and Spiro-OMeTAD as electron and hole transporting materials) and different ratio of MAI and $\mathrm{Pbl}_{2}\left(\mathrm{MAl} / \mathrm{Pb}_{2}=0.9,1.0\right)$ was investigated by Atomic Force Microscopy $(\mathrm{AFM})$ and Kelvin probe. All samples were measured repeatedly during 28 days.

\section{MATERIALS AND METHODS}

Samples were made according to estabslihed protocol [12]. The Indium Tin Oxides (ITO) substrates were cleaned. $\mathrm{SnO}_{2}$ solution were then spin-coated on substrates as the electron transport layer (ETL). The thickness was around $40 \mathrm{~nm}$. Methylamine iodide and lead (II) iodide were predissolved in N, N- 
dimethylformamide as precursor solution before spin-coating process. After $\mathrm{SnO}_{2}$ annealing, $\mathrm{MAPbl}_{3}$ precursor solution was then spin-coated on ETL as an intrinsic layer at $3000 \mathrm{rpm}$ for $20 \mathrm{~s}$. The thickness of perovskite film was around $300 \mathrm{~nm}$. The iodine was doped into the spiro-OMeTAD solution in different concentrations. The dopant was varied from $0 \mathrm{mg} / \mathrm{mL}$ to $15 \mathrm{mg} / \mathrm{mL}$ in a gradient of $3 \mathrm{mg} / \mathrm{mL}$. The perovskite samples with $\mathrm{MAl} / \mathrm{Pbl} 2$ ratios 0.9 and 1.0 and CTLs with and without were investigated by AFM (AC mode, $75 \mathrm{kHz}$ tip) using WITec Alpha 300 RAS system and software Control 5.1. Data acquisition and processing were done by the WITec Control and Project Five 5.1 software. The work function and photovoltage of the samples with and without CTLs were investigated by Kelvin Probe (KP Technology) in Faraday cage in the dark and under illumination with a switching on/off period of three minutes. Thereby obtained photovoltage can be related to open-circuit voltage $\left(V_{o c}\right)$ of the device [13]. The Kelvin Probe measurements were repeated after 14 and 28 days.

\section{RESULTS AND DISCUSSION}

\subsection{Optical and Atomic Force Microscopy characterization}

Figure 1 shows optical and AFM topography images of the samples, where PVSK stands for perovskite. The optical images show flat surface with occasional black spots. A mechanical scratch is also noticeable in the ITO/PVSK and ITO/SnO $/$ PVSK images.

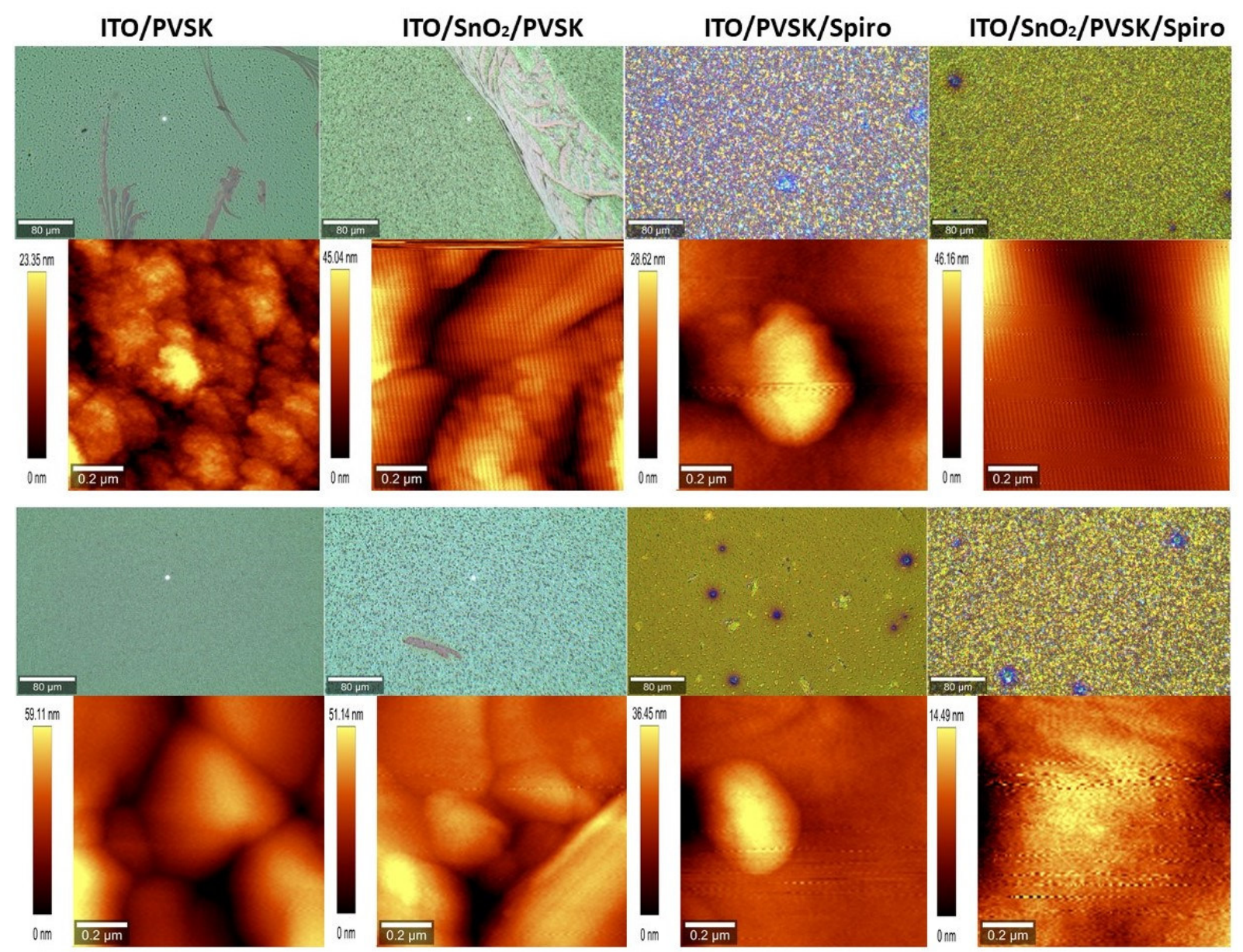

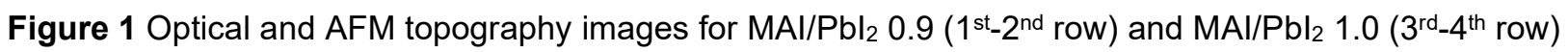
without and with various CTLs combinations 
Otherwise not much differences can be identified in the optical images. On the other hand, the AFM images illustrate that both CTLs and MAI can influence the morphology of the perovskite. ITO/PVSK and $\mathrm{ITO} / \mathrm{ETL} / \mathrm{PVSK}$ with $\mathrm{MAI} / \mathrm{Pbl} \mathrm{I}_{2}=1.0$ seems to have somewhat smoother surfaces and bigger grains $(\sim 57 \mathrm{~nm}$ height, $\sim 430 \mathrm{~nm}$ diameter) compared to the samples with $\mathrm{MAl} / \mathrm{Pbl}_{2}=0.9(\sim 23 \mathrm{~nm}$ height, $\sim 180 \mathrm{~nm}$ diameter). AFM images of samples with $\mathrm{SnO}_{2}$ (rows 2 and $4,2^{\text {nd }}$ column) exhibit similar structure as ITO/PVSK, only there is noticeably less of fine structured grains. The deposition of $\mathrm{SnO}_{2}$ on the ITO surface thus helped reduce granularity and improved PVSK uniformity. After the Spiro coating the surface roughness (Sq) of the samples reduced significantly (for MAl/Pbl $2=0.9: \mathrm{Sq}\left(\mathrm{ITO} / \mathrm{SnO}_{2} / \mathrm{PVSK}\right) \approx 988 \mathrm{~nm}, \mathrm{Sq}\left(\mathrm{ITO} / \mathrm{SnO}_{2} / \mathrm{PVSK} / \mathrm{Spiro}\right) \approx 81 \mathrm{~nm}$; for $\left.\mathrm{MAl} / \mathrm{Pbl}_{2}=1.0: \mathrm{Sq}\left(\mathrm{ITO} / \mathrm{SnO}_{2} / \mathrm{PVSK}\right) \approx 34 \mathrm{~nm}, \mathrm{Sq}\left(\mathrm{ITO} / \mathrm{SnO}_{2} / \mathrm{PVSK} / \mathrm{SpirO}\right) \approx 29 \mathrm{~nm}\right)$. The Spiro is thus filling the rough surface rather than being conformal. Topography images of ITO/PVSK/Spiro samples still show some noticeable crystal structures (15 nm high with diameter $35 \mathrm{~nm}$ ), which are less pronounced in the samples with $\mathrm{SnO}_{2}$ layer deposited below the PVSK (Figure 1, $4^{\text {th }}$ column, rows 2 and 4). Thus, the complete layer stack with both CTLs provides the best overall PVSK uniformity. This may be important feature for homogeneous charge collection via CTLs and reducing degradation due to ion migration.

\subsection{Kelvin Probe study}

The influence of CTLs and PVSK morphology on materials work function (WF), photovoltage (PV) and stability in time was studied by Kelvin probe. Figure 2 shows the results for the samples with ratio $\mathbf{M A I} / \mathbf{P b I}_{2}=\mathbf{0 . 9}$. The sample with ITO/PVSK (Figure 2A) was stable, with WF of $4.96 \pm 0.03 \mathrm{eV}$ in the dark for the whole period of 28 days. The PV was negative (seen as higher work function after illumination) and remained also more or less stable $(-0.19 \mathrm{~V})$ during 28 days. The negative PV means that electrons were not extracted to the bottom electrode but rather diffused to the PVSK surface.

Work function of the ITO/PVSK/Spiro sample was also stable $(5.28 \pm 0.02 \mathrm{eV})$ without significant changes during 28 days (Figure 2B). However, the PV response was small $-0.4 \mathrm{~V}$ after 28 days. This means that Spiro was actually able to extract some holes to the surface and thereby compensated the negative photovoltage of PVSK.

In the ITO/SnO $/$ PVSK sample (Figure 2C) the WF was lowered (4.59 $\pm 0.07 \mathrm{eV}$ ) compared to ITO/PVSK samples. There was also some persistent charging observed during the short-term light on-off switching. The WF in dark fluctuated between $4.73 \pm 0.06 \mathrm{eV}$ and $4.54 \pm 0.06 \mathrm{eV}$ during 28 days. The PV also fluctuated between $-0.38 \mathrm{~V}$ and $-0.17 \mathrm{~V}$ during 28 days, even some increase in time was observed. The ITO/SnO $/ \mathrm{PVSK}$ system is thus largely unstable. Moreover, overall photovoltage remained negative. Hence, even with ETL, electrons were not extracted but rather diffused to the PVSK surface.

Figure 2D displays work function and photovoltage for the complete ITO/SnO $2 / \mathrm{PVSK} / \mathrm{Spiro}$ sample. The WF in dark decreases from $5.33 \pm 0.07 \mathrm{eV}$ to $5.09 \pm 0.07 \mathrm{eV}$ during 28 days. Photovoltage is positive in this case, compared to all other samples. Thus, only with the complete layer stack the PVSK operates as expected, i.e. holes are collected by Spiro HTL on the surface and electrons are transported to bottom $\mathrm{SnO}_{2} \mathrm{ETL}$. It is surprising that the PV is negative on the sample even with Spiro in the absence of $\mathrm{SnO}_{2}$ at the bottom. Thus, the Spiro-PVSK interface is not working correctly in that case, most likely because of different PVSK structure on ITO compared to ITO/SnO 2 as indicated by AFM data above.

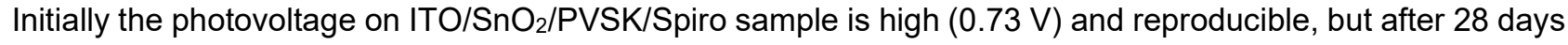
there is again some persistent charging observed during the short-term light on/off switching. The PV also progressively decreases from $0.73 \mathrm{~V}$ to $0.19 \mathrm{~V}$ after 28 days. This decrease evidences degradation of the material (or more precisely of the layer stack) properties with large contribution from $\mathrm{SnO}_{2}$. This is most likely due to ion migration as indicated by a slower kinetics during the light on/off switching.

Figure 3 shows Kelvin probe measurement results of the samples with $\mathbf{M A l} / \mathbf{P b l}_{\mathbf{2}}=\mathbf{1 . 0}$ with and without CTLs. For ITO/PVSK samples, the WF measured in the dark $(5.1 \pm 0.1 \mathrm{eV})$ decreased in time $(4.6 \pm 0.1 \mathrm{eV}$ and 4.7 $\pm 0.1 \mathrm{eV}$ after 14 and 28 days, respectively). The PV fluctuated between $-0.18 \mathrm{~V}$ and $-0.78 \mathrm{~V}$ during 28 days. 

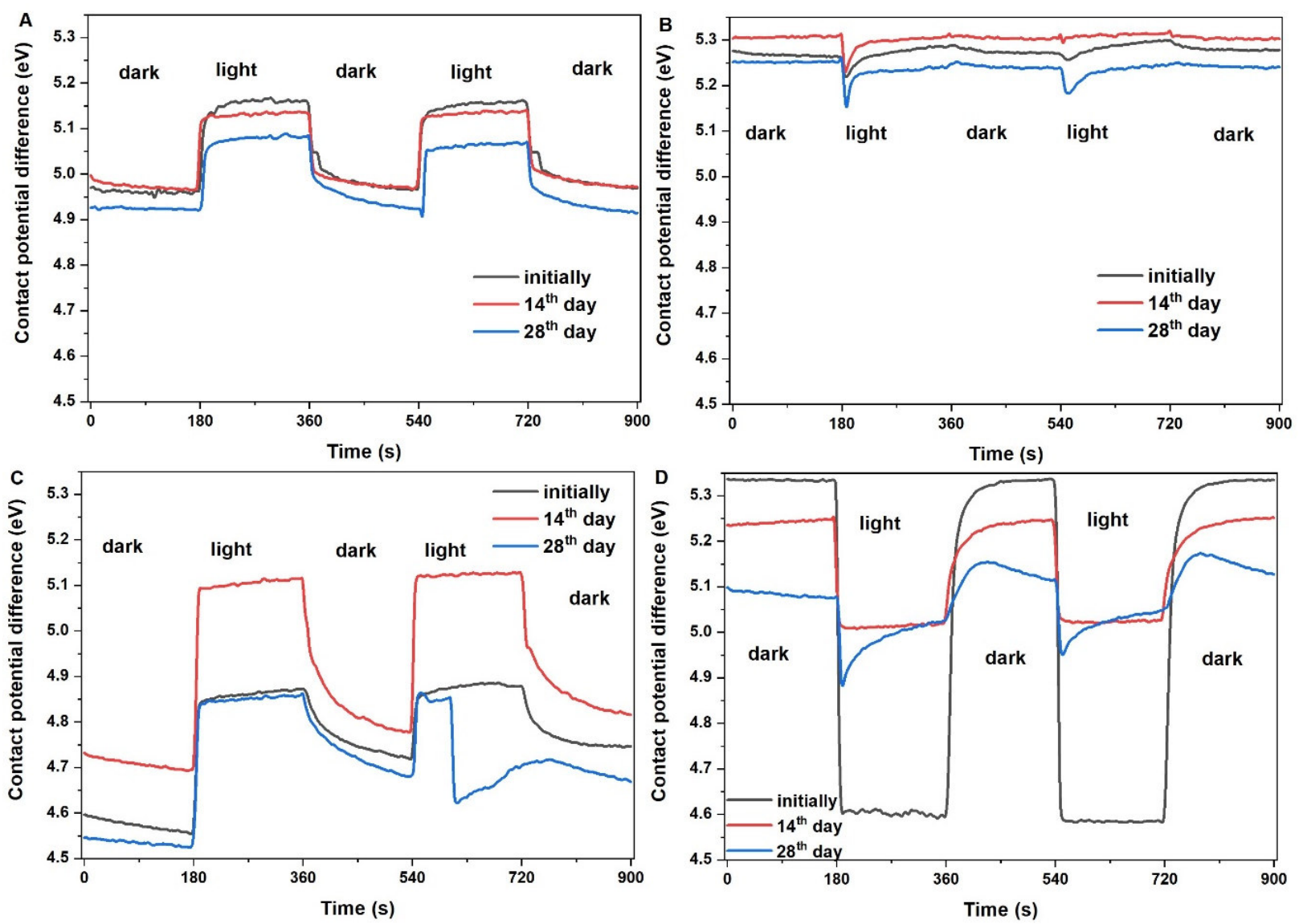

Figure 2 Kelvin probe study of degradation for $\mathrm{MAl} / \mathrm{Pbl}_{2}=0.9$ in the dark and under illumination with a switching on/off period of $180 \mathrm{~s}$ and degradation period for 28 days: A ITO/PVSK, B ITO/PVSK/Spiro,

C ITO/SnO $/$ PVSK, D ITO/SnO $/$ PVSK/Spiro.

The WF in ITO/PVSK/Spiro sample (Figure 3B) was stable $(5.19 \pm 0.06 \mathrm{eV})$ for 14 days after 28 days decreased $(5.03 \pm 0.06 \mathrm{eV})$. The $\mathrm{PV}$ response was higher and clearly positive $(0.26 \mathrm{~V})$ compared to the sample with $\mathrm{MAl} / \mathrm{Pbl}_{2}=0.9$. The positive $\mathrm{PV}$ means that holes were extracted by Spiro. Also, a kinetics in ITO/PVSK/Spiro was slower during the light on/off switching compared to the sample with $\mathrm{MAI} / \mathrm{Pbl}_{2}=0.9$.

The WF in ITO/SnO $/$ PVSK (Figure 3C) fluctuated between $4.71 \pm 0.03 \mathrm{eV}$ and $4.97 \pm 0.03 \mathrm{eV}$ during 28 days. The photovoltage fluctuation between $-0.20 \mathrm{~V}$ and $-0.05 \mathrm{~V}$ was observed during 28 days as well. The kinetics process during switching on/off in ITO/SnO $/$ PVSK was slower compared to the same sample with $\mathrm{MAl} / \mathrm{Pbl}_{2}$ $=0.9$

For the complete ITO/SnO $/ \mathrm{PVSK} /$ Spiro layer stack (Figure 3D) the WF in dark decreased from $5.26 \pm 0.06$ to $5.02 \pm 0.06 \mathrm{eV}$ during 28 days. The $\mathrm{PV}$ is positive in this case, also as in the ITO/SnO $/ \mathrm{PVSK} / \mathrm{Sp}$ iro with $\mathrm{MAl} / \mathrm{Pbl}_{2}=0.9$. The function of CTLs is thus the same as described above for the sample with $\mathrm{MAl} / \mathrm{Pbl}_{2}=0.9$. However, photovoltage is smaller and more unstable. Initially the PV on ITO/SnO $/ \mathrm{PVSK} / \mathrm{Spiro}$ sample is $0.32 \mathrm{~V}$, after 14 days it increases to $0.51 \mathrm{~V}$, and then decrease to $0.16 \mathrm{~V}$ after 28 days.

The observed effects are generally similar as for the samples with $\mathrm{MAl} / \mathrm{Pbl}_{2}=0.9$. Yet there are some differences. Even for the same CTLs layers there was slower kinetics during the light on/off switching and photovoltages were much more fluctuating. These effects of the excess MAI are most likely due to more pronounced ion migration effects. This is correlated with difference in PVSK structure as hinted by AFM morphology. 

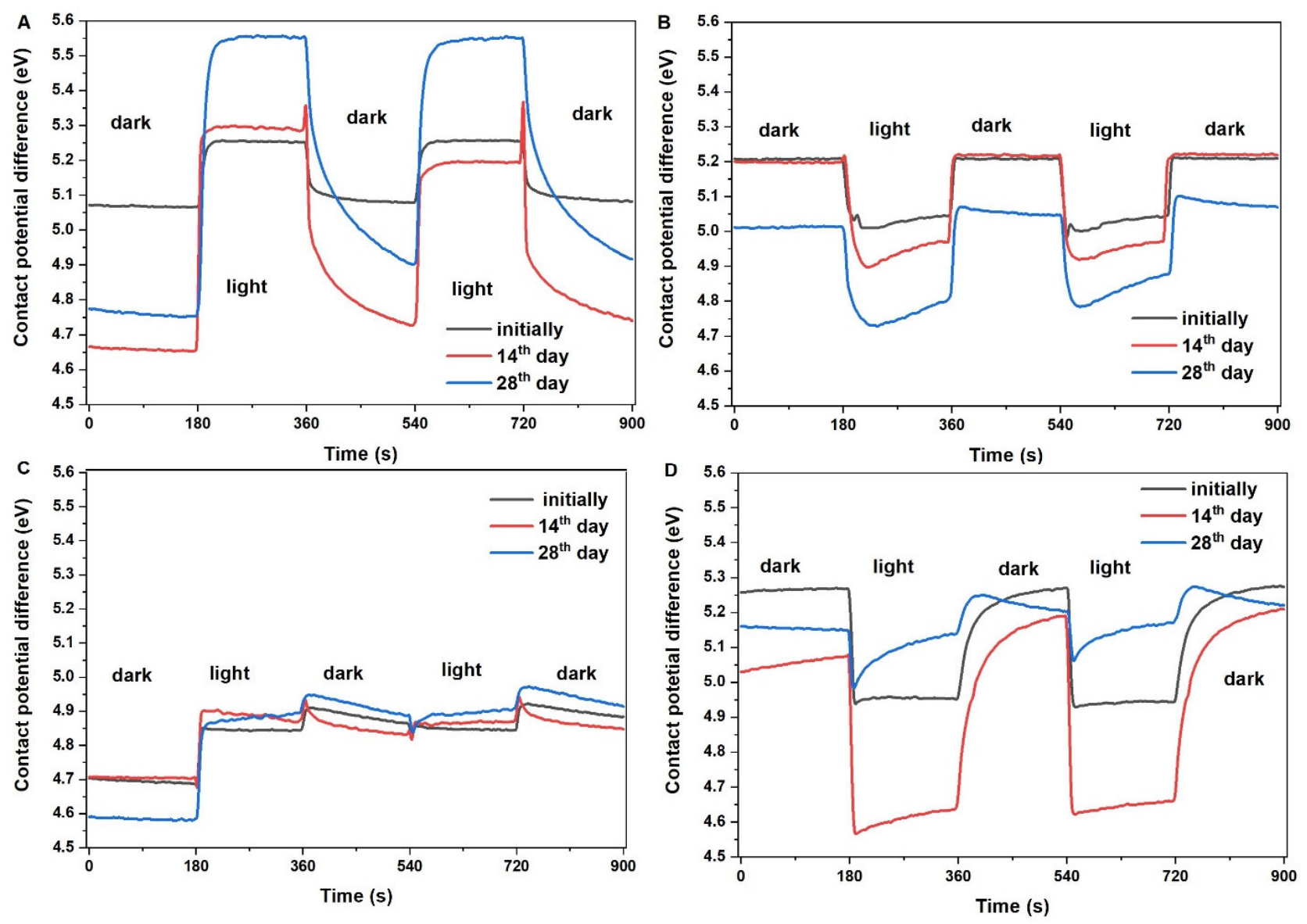

Figure $3 \mathrm{Kelvin}$ probe study of degradation for $\mathrm{MAI} / \mathrm{Pbl}_{2}=1.0$ in the dark and under illumination with a switching on/off period of $180 \mathrm{~s}$ and degradation period for 28 days: A ITO/PVSK, B ITO/PVSK/Spiro, C ITO/SnO $/$ /PVSK, D ITO/SnO2/PVSK/Spiro.

\section{CONCLUSION}

In this work the impact of precursor stoichiometry (methylamonium (MAI) and $\mathrm{Pbl}_{2}$ ), granularity, and charge transporting layers (CTLs) on the properties and degradation of $\mathrm{MAPbl}_{3}$ perovskite was observed. The influence of CTLs $\left(\mathrm{SnO}_{2}\right.$ and Spiro-OMeTAD) and different ratio of $\mathrm{MAl}$ and $\mathrm{Pbl}_{2}\left(\mathrm{MAl} / \mathrm{Pb}_{2}=0.9,1.0\right)$ on morphology, ion migration and degradation were analysed by AFM and Kelvin Probe. The optical and AFM images overall illustrate how both CTLs and MAI can in certain degree influence the morphology of the perovskite. The optical images do not show much structural differences. On the other hand, the AFM morphology images showed effect of CTLs and MAI on surface properties as size of grains and roughness. Kelvin probe study revealed that also the surface work function, photovoltage including kinetics and direction of charge extraction as well as overall stability depend on CTLs and content of MAI. Thereby the Kelvin Probe results also indicated that the excess $\mathrm{Pbl}_{2}$ has influence on ion migration. The changes of the photovoltage kinetics on samples coated with Spiro indicated also possible structural differences in PVSK layer that could not be observed directly by AFM on surface.

\section{ACKNOWLEDGEMENTS}

The work was supported by the project CZ.02.1.01/0.0/15_003/0000464

Centre of Advanced Photovoltaics. 


\section{REFERENCES}

[1] CHEN, Qi, DE MARCO, Nicholas, YANG, Yang (Michael), SONG, Tze-Bin, CHEN, Chun-Chao, ZHAO, Hongxiang, HONG, Ziruo, ZHOU, Huanping and YANG, Yang. Under the spotlight: The organic-inorganic hybrid halide perovskite for optoelectronic applications. Nano Today [online]. 1 June 2015. Vol. 10, no. 3, p. 355-396. [Accessed 15 January 2019]. https://doi.org/10.1016/J.NANTOD.2015.04.009.

[2] XIA, Jianxing, LUO, Junsheng, YANG, Hua, SUN, Chunlin, WAN, Zhongquan, MALIK, Haseeb Ashraf, ZHANG, Haoli, SHI, Yu and JIA, Chunyang. lonic selective contact controls the charge accumulation for efficient and intrinsic stable planar homo-junction perovskite solar cells. Nano Energy [online]. 1 December 2019. Vol. 66, p. 104098. [Accessed 10 October 2019]. https://doi.org/10.1016/j.nanoen.2019.104098.

[3] SNAITH, Henry J., ABATE, Antonio, BALL, James M., EPERON, Giles E., LEIJTENS, Tomas, NOEL, Nakita K., STRANKS, Samuel D., WANG, Jacob Tse-Wei, WOJCIECHOWSKI, Konrad and ZHANG, Wei. Anomalous Hysteresis in Perovskite Solar Cells. The Journal of Physical Chemistry Letters [online]. 10 May 2014. Vol. 5, no. 9, p. 1511-1515. [Accessed 27 September 2019]. https://doi.org/10.1021/jz500113x.

[4] TRESS, W., MARINOVA, N., MOEHL, T., ZAKEERUDDIN, S. M., NAZEERUDDIN, Mohammad Khaja and GRÄTZEL, M. Understanding the rate-dependent J-V hysteresis, slow time component, and aging in $\mathrm{CH}_{3} \mathrm{NH}_{3}$ $\mathrm{Pbl} 3$ perovskite solar cells: the role of a compensated electric field. Energy \& Environmental Science [online]. 5 March 2015. Vol. 8, no. 3, p. 995-1004. [Accessed 22 October 2019]. https://doi.org/10.1039/C4EE03664F.

[5] UNGER, E. L., HOKE, E. T., BAILIE, C. D., NGUYEN, W. H., BOWRING, A. R., HEUMÜLLER, T., CHRISTOFORO, M. G. and MCGEHEE, M. D. Hysteresis and transient behavior in current-voltage measurements of hybrid-perovskite absorber solar cells. Energy Environ. Sci. [online]. 2014. Vol. 7, no. 11, p. 3690-3698. [Accessed 22 October 2019]. https://doi.org/10.1039/C4EE02465F.

[6] YUAN, Yongbo and HUANG, Jinsong. Ion Migration in Organometal Trihalide Perovskite and Its Impact on Photovoltaic Efficiency and Stability. Accounts of Chemical Research [online]. 16 February 2016. Vol. 49, no. 2, p. 286-293. [online]. https://doi.org/10.1021/acs.accounts.5b00420.

[7] ZHAO, Xiaojuan and WANG, Mingkui. Organic hole-transporting materials for efficient perovskite solar cells. Materials Today Energy [online]. 2018. Vol. 7, p. 208-220. https://doi.org/10.1016/..mtener.2017.09.011.

[8] LEE, Jin Wook, BAE, Sang Hoon, DE MARCO, Nicholas, HSIEH, Yao Tsung, DAI, Zhenghong and YANG, Yang. The role of grain boundaries in perovskite solar cells. Materials Today Energy [online]. 2018. Vol. 7, p. 149-160. https://doi.org/10.1016/j.mtener.2017.07.014.

[9] ZHENG, Xiaopeng, CHEN, Bo, DAI, Jun, FANG, Yanjun, BAl, Yang, LIN, Yuze, WEI, Haotong, ZENG, Xiao Cheng and HUANG, Jinsong. Defect passivation in hybrid perovskite solar cells using quaternary ammonium halide anions and cations. Nature Energy [online]. 26 July 2017. Vol. 2, no. 7, p. 17102.

[Accessed 11 October 2019]. https://doi.org/10.1038/nenergy.2017.102.

[10] LEIJTENS, Tomas, EPERON, Giles E., BARKER, Alex J., GRANCINI, Giulia, ZHANG, Wei, BALL, James M., KANDADA, Ajay Ram Srimath, SNAITH, Henry J. and PETROZZA, Annamaria. Carrier trapping and recombination: the role of defect physics in enhancing the open circuit voltage of metal halide perovskite solar cells. Energy \& Environmental Science [online]. 2016. Vol. 9, no. 11, p. 3472-3481. [Accessed 11 October 2019]. https://doi.org/10.1039/C6EE01729K.

[11] PENG, Jun, WU, Yiliang, YE, Wang, JACOBS, Daniel A., SHEN, Heping, FU, Xiao, WAN, Yimao, DUONG, The, WU, Nandi, BARUGKIN, Chog, NGUYEN, Hieu T., ZHONG, Dingyong, LI, Juntao, LU, Teng, LIU, Yun, LOCKREY, Mark N., WEBER, Klaus J., CATCHPOLE, Kylie R. and WHITE, Thomas P. Interface passivation using ultrathin polymer-fullerene films for high-efficiency perovskite solar cells with negligible hysteresis. Energy \& Environmental Science [online]. 2017. Vol. 10, no. 8, p. 1792-1800. [online]. https://doi.org/10.1039/C7EE01096F.

[12] LIU, Guilin, LIU, Lang, NIU, Xiuxiu, ZHOU, Huanping and CHEN, Qi. Effects of lodine Doping on Carrier Behavior at the Interface of Perovskite Crystals: Efficiency and Stability. Crystals [online]. 25 April 2018. Vol. 8, no. 5, p. 185. [Accessed 3 November 2019]. https://doi.org/10.3390/cryst8050185.

[13] ELUMALAI, Naveen Kumar and UDDIN, Ashraf. Open circuit voltage of organic solar cells: an in-depth review. Energy \& Environmental Science [online]. 9 February 2016. Vol. 9, no. 2, p. 391-410. [online].

https://doi.org/10.1039/C5EE02871J. 